\title{
Long-Span Wooden Structural Floors with Self-Tensioning System: Performance under Asymmetrical Loads
}

\author{
J. Estévez-Cimadevila, D. Otero-Chans, E. Martín-Gutiérrez, and F. Suárez-Riestra \\ Department of Construction Technology, Universidade da Coruña, A Coruña, Spain \\ Correspondence should be addressed to J. Estévez-Cimadevila; javier@udc.es
}

Received 1 June 2016; Accepted 7 July 2016

Academic Editor: Ana S. Guimarães

Copyright ( 2016 J. Estévez-Cimadevila et al. This is an open access article distributed under the Creative Commons Attribution License, which permits unrestricted use, distribution, and reproduction in any medium, provided the original work is properly cited.

This study analyzes the performance of wooden structural floors equipped with the self-tensioning system patented by the authors, consisting of a force multiplying mechanism connected to a self-tensioning tendon, which is activated automatically when the load is applied to the structural element. The paper describes the system's difficulties when the structural floor is subjected to asymmetrical loads. The proposed solution consists of anchoring the tendon by an adhesive connection in the central part of the piece yielding a favorable redistribution of the bending moments and an effective performance in terms of deformations. The comparative study focuses on $\pi$-shape cross section pieces with spans of $12 \mathrm{~m}$ and $15 \mathrm{~m}$, using sections without prestressing and with initial prestressing and self-tensioning system.

\section{Introduction}

Traditionally, the application of prestressing has been focused on concrete structures subjected to bending, with the goal of compensating its low tensile resistance using precompression. In the case of wood, its high tensile strength has been one of the main reasons why tensioning solutions have not been widely developed.

The difficulty of making rigid connections with wood means that deflected pieces have frequently been used and arranged over simple supports. The rotation freedom inherent to this type of support generates inefficient bending stresses and provokes the dimensioning to be strongly conditioned by deformation limitations. In the conditions where the pieces are mounted on two supports, prestressing techniques provide effective solutions to improve the performance, in terms of both resistance and deformations.

Traditionally, prestressing of deflected pieces of wood has been carried out using bonded tendons. These tendons are made using steel bars or plates [1-5] or by using FRP fibre-reinforced polymer [2, 6-10]. The tendons subjected to tension are linked to the wood by adhesive connections, usually using epoxy or polyurethane-based adhesives. Once the adhesive has cured and the jack used for tensing the tendon has been removed, the wood is subjected to compression. Normally, the tendons are placed eccentrically as they generate a precamber in the piece.

Additionally, gravitational loads cause a more effective distribution of the bending stress along the axis of the structural element. One of the main problems arising from tensioning systems using bonded tendons is the delamination in the anchorage area due to the high stresses concentration $[11,12]$.

Besides the use of bonded tendons, other solutions have also been studied with unbonded tendons that are tensioned when the structural element is bearing loads. These solutions have been employed in timber frames [13-15] and also to improve the performance of beam-column connections $[16$, 17]. Another newly developed strengthening technique to prestress glued laminated timber consists of inserting compressed wood blocks with lower moisture content than the ambient one, into the precut rectangular holes on the top part of the glulam beams [18].

\section{Self-Tensioning System}

In deflected pieces mounted on two supports, the design is determined by the compliance with the conditions of 


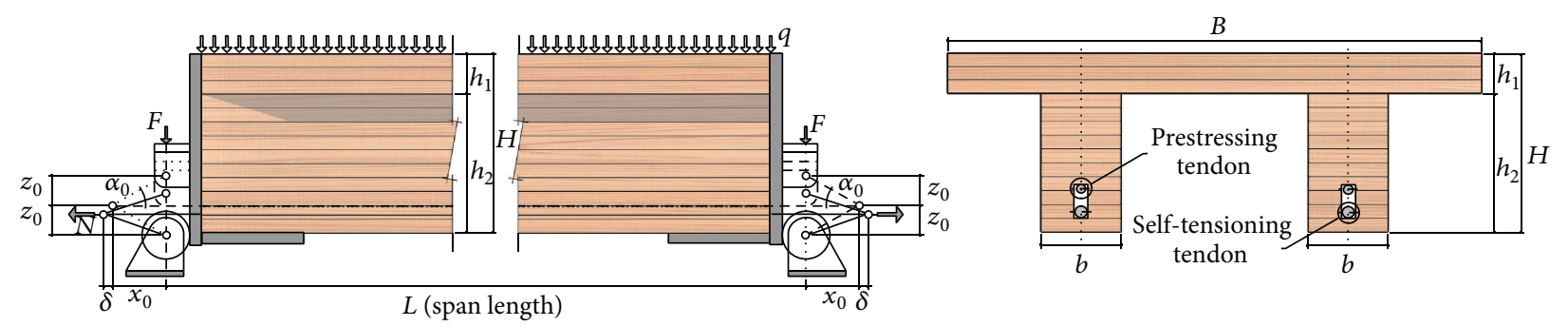

Figure 1: Multiplier device using a system of rods and $\pi$-shape cross section of structural floor.

deformation. One way to counteract this limitation is to manufacture pieces with a precamber. Another option is to carry out an initial prestress. However, the efficiency of both solutions depends on whether the pieces have a camber limitation based on the desired appearance of the work. When the condition limiting the design is the integrity of the construction elements (damage in pavement, ceilings, etc.), the effectiveness of the solution using manufactured precamber or initial pretension is affected when there are significant variable actions. This means that, in the case of long-span structural floors, usually associated with publicuse buildings with loads varying between $3 \mathrm{kN} / \mathrm{m}^{2}$ and $5 \mathrm{kN} / \mathrm{m}^{2}$, the use of an initial precamber does not completely solve the significantly large variations in the deformations produced in the structural element during its service life. Therefore, this requires increasing the height of the structural elements to gain rigidity.

A highly effective solution for resolving this situation is the one involving the self-tensioning system patented by the authors [19]. It consists of a force-multiplier device made up of two connecting rods anchored to an eccentric tendon (Figure 1). When the structural element begins to bear external loads, the forces transmitted to the supports make the tendon automatically tighten. The tensioning force magnitude and, therefore, the value of the bending moment generated by its eccentricity vary depending on the acting loads, rising and reducing accordingly. The use of the self-tensioning device in combination with an initial prestress enables the construction of slenderer structural timber floors conceived for public use, yielding in all studied cases, to relative deformations below $1 / 1000$ of the span in service loads conditions.

\section{System Performance under Symmetrical Loads}

To show the effectiveness of the abovementioned self-tensioning device, we have analyzed the performance of $\pi$-shape cross section pieces with the following characteristics:

(i) Span length $L=15 \mathrm{~m}$.

(ii) $\pi$-shape cross section conformed by two laminated timber ribs of GL28h strength class [20] and an upper board of cross laminated timber CLT90S L3S formed by three $30 \mathrm{~mm}$ sheets of picea abies C24, with a total thickness of $90 \mathrm{~mm}$ [21].
Material properties of glued laminated timber GL28h:

Bending strength: $f_{m, g, k}(28 \mathrm{MPa})$.

Tensile strength in the direction of the grain: $f_{t, 0, g, k}(22,3 \mathrm{MPa})$.

Tensile strength perpendicular to the grain: $f_{t, 90, g, k}(0,5 \mathrm{MPa})$.

Compression strength in the direction of the grain: $f_{c, 0, g, k}(28 \mathrm{MPa})$.

Compression strength perpendicular to the grain: $f_{c, 90, g, k}(2,5 \mathrm{MPa})$.

Shear strength: $f_{v, k}(3,5 \mathrm{MPa})$.

Modulus of elasticity parallel to the grain: $E_{0 \text {,mean }}(12.600 \mathrm{MPa})$.

Shear modulus: $G_{\text {mean }}(650 \mathrm{MPa})$.

Characteristic density: $\rho_{k}\left(425 \mathrm{~kg} / \mathrm{m}^{3}\right)$.

Material properties of cross laminated timber:

Bending strength: $f_{m, k}(24 \mathrm{MPa})$.

Tensile strength in the direction of the grain: $f_{t, 0, k}(14 \mathrm{MPa})$.

Compression strength in the direction of the grain: $f_{c, 0, k}(21 \mathrm{MPa})$.

Shear strength parallel to the grain of the boards: $f_{v, k}(2,5 \mathrm{MPa})$.

Modulus of elasticity parallel to the grain of the boards: $E_{0 \text {,mean }}(12.500 \mathrm{MPa})$.

Shear modulus parallel to the grain of the boards: $G_{\text {mean }}(460 \mathrm{MPa})$.

Characteristic density: $\rho_{k}\left(420 \mathrm{~kg} / \mathrm{m}^{3}\right)$.

(iii) Cross section's dimensions (Figure 1):

$b=180 \mathrm{~mm} ; B=1200 \mathrm{~mm} ; H=0,030 ; H=$ $450 \mathrm{~mm} h 1=360 \mathrm{~mm} ; h 2=90 \mathrm{~mm}$.

(iv) Two types of sections evaluated:

(S1) Section with no prestress and no initial precamber.

(S2) Prestressed section with a $L / 500$ precamber and the self-tensioning system.

(v) Self-tensioning system using rods with an initial angle of $\alpha_{0}=26,57^{\circ}$, corresponding to initial dimensions of $x_{0}=100 \mathrm{~mm}$ and $z_{0}=50 \mathrm{~mm}$, and a self-tensioning tendon with an area of $\Omega=900 \mathrm{~mm}^{2}$ (Figure 1). For 
the prestressing of the pieces, a steel $\mathrm{Y} 1100 \mathrm{H}$ [22] has been considered with elastic limit $f_{p k}=900 \mathrm{~N} / \mathrm{mm}^{2}$, tensile strength $f_{\text {pmax }, k}=1.100 \mathrm{~N} / \mathrm{mm}^{2}$, and modulus of elasticity $E=205.000 \mathrm{~N} / \mathrm{mm}^{2}$.

A total uniformly distributed load of $G_{k}=2.07 \mathrm{kN} / \mathrm{m}^{2}$ has been adopted. This includes the self-weight of the element $\left(1.07 \mathrm{kN} / \mathrm{m}^{2}\right)$ and the finishing elements $\left(1.00 \mathrm{kN} / \mathrm{m}^{2}\right)$. To determine the variable loads, an office use was considered, given that this is the normal situation in which large-span structural floors are used. For this type of use, the regulations assign the value $Q_{k}=3 \mathrm{kN} / \mathrm{m}^{2}$ [23], and $\Psi_{2}=0.3$ is adopted as a factor for the quasipermanent value of variable loads. In the analysis, the following load hypotheses are considered:

(H0) No load, initial position.

(H1) Permanent load, $G_{k}=2.07 \mathrm{kN} / \mathrm{m}^{2}$.

(H2) Quasipermanent load, $G_{k}+\Psi_{2} \cdot Q_{k}=2.97 \mathrm{kN} / \mathrm{m}^{2}$.

(H3) Total load, $G_{k}+Q_{k}=5.07 \mathrm{kN} / \mathrm{m}^{2}$.

For the analysis of the system, it is necessary to take into account that the applied tensioning force depends on the geometry of the multiplier device. As the acting load increases, a significant variation of its geometry is produced, giving rise to a nonlinear behaviour whose importance increases inasmuch as the load value increases. This nonlinear behaviour is positive for the tensioning effects because the increasing of the deflection of the device leads to an increasing of its multiplier effect $(\mathfrak{X})$ and, consequently, of the force applied on the ends of the beam. To take into account the geometric nonlinearity of the described system, the analysis used an incremental load process in which, at each stage, the multiplier effect corresponding to its state of deformation is taken into account.

Self-tensioning force at instant $i$ is

$$
N_{i}=\mathfrak{X}_{i} F_{i}=\frac{x_{i}}{z_{i}} q_{i} L
$$

New multiplier is as follows:

$$
\mathfrak{X}_{i+1}=2 \frac{x_{i}+\delta_{i}}{z_{i}-\sqrt{z_{i}^{2}-2 x_{i} \delta_{i}-\delta_{i}^{2}}} .
$$

In determining the multiplier effect, the consideration of the elastic shortening of the rods has been bypassed, of worthless magnitude in comparison with the lengthening experienced by the tendon. Therefore, the elastic shortening of the wooden piece has not been considered because its magnitude is very reduced due to its high axial stiffness and, besides, its effect would be favorable by increasing the deflection of the multiplier device and, consequently, the self-tensioning force. Finally, in the contact between the connecting rods, the consideration of friction has been omitted. We have analyzed the behaviour of the mechanism by FEM model with software that allows defining different friction coefficients for each part (frictional contact and contact stiffness). The experimental

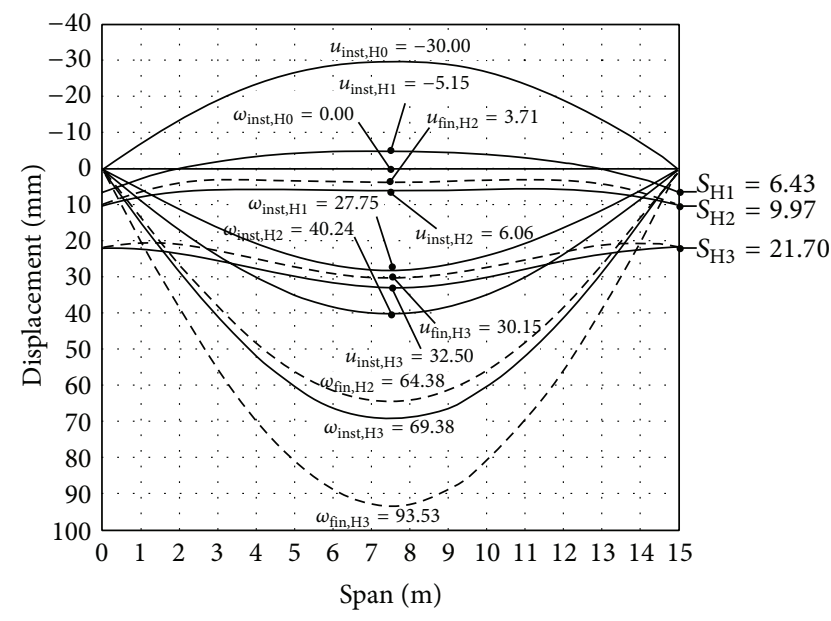

FIGURE 2: Bending deformations of $\pi$ section pieces with no prestressing (S1) and pieces with prestressing and a self-tensioning system (S2). $L=15 \mathrm{~m} ; B=600 \mathrm{~mm} ; b=180 \mathrm{~mm} ; H=450 \mathrm{~mm}$; $h_{1}=360 \mathrm{~mm} ; h_{2}=90 \mathrm{~mm} ; \alpha_{0}=26.57^{\circ}$.

phase will determine the appropriate parameters. In any case, the initial results show that the geometry arranged in the mechanism reduces the possibility of prestressing force loss.

The calculation of the creep deformations of the quasipermanent fraction was determined using a factor of $k_{\text {def }}=$ 0.6 corresponding to service class 1 , in accordance with the following expression [24]:

$$
\omega_{\text {fin }}=\omega_{\text {inst }}+\omega_{\text {creep }}=\omega_{\text {inst }}\left(1+k_{\text {def }} \Psi_{2}\right) .
$$

When performing the deformations calculations, it is important to take into account a small descent at the supports of the structural element when the mechanic device starts to bear external loads (Figure 1). The value of this displacement depends on the geometry of the multiplying device and on the rigidities of the structural elements. The deflection $(\omega)$ is the difference between the displacement at the midspan of the element $(u)$ and the seat at the supports $(s)$.

In Figure 2, deformations corresponding to $\pi$-shape cross section pieces with no prestress ( $\mathrm{S} 1$ ) and pieces with prestressing and self-tensioning system (S2) are shown. The instant deformations corresponding to the $(\mathrm{H} 2)$ load hypothesis (quasipermanent loads) reach the value of $40.24 \mathrm{~mm}$ in pieces without prestressing. This value reduces to $6.06 \mathrm{~mm}$ when the piece is prestressed and has a self-tensioning device. In terms of relative deflection, the supports of the tensioned piece experiment a seat of $9.97 \mathrm{~mm}$ in the (H2) hypothesis, causing a relative deflection of $9.97-6.06=3.91 \mathrm{~mm}$. This relative deflection of $3.91 \mathrm{~mm}$ represents a distortion of $L / 3836$ versus the value of $L / 373$ corresponding to the piece with no prestressing.

If we consider the creep deformations for this (H2) load hypothesis, the deflection of the structural floor without prestressing is $64.38 \mathrm{~mm}$ (Figure 2). This means that the creep deformations increase the value of the deflection by 64.38 $40.24=24.14 \mathrm{~mm}$. By contrast, for pieces with the tensioning system, taking into account that creep deformations mean less of a decrease in the (H2) hypothesis, the value goes from 


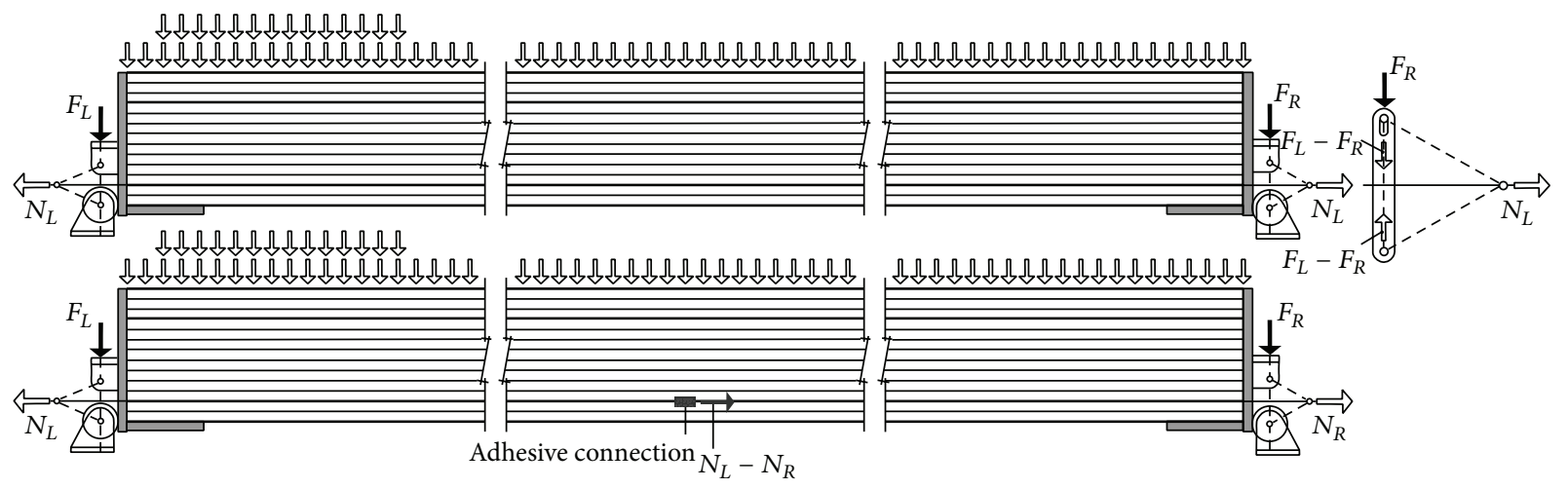

FIGURE 3: Drawing of lock position at the support (beam above) and tendon anchored in the central section (beam below).

$6.60 \mathrm{~mm}$ to $3.71 \mathrm{~mm}$. This is due to the positive effect of the pretensioning, since its permanent load means that the precamber produced at the moment of tensioning increases over time. Studying the situation in terms of relative deflection, while the distortion of the tensioned piece is $L / 2396$, for the piece with no prestressing, this value increases to $L / 233$, which represents a distortion 10 times greater.

Comparing the performances of both piece types, in the case of the (H3) hypothesis corresponding to the total load, similar results are obtained. For the tensioned piece, the relative deflection reaches a value of $L / 1775$ which increases to $L / 160$ when the piece does not have the tensioning system.

The results demonstrate the high efficiency of the system in regard to deformations, as it means that slenderer longspan pieces can be installed, maintaining very low distortion levels under service loads conditions.

However, the efficiency improvement of the system is achieved not only in deformation but in terms of resistance as well. The maximum breaking strain characteristic value of a nonstressed $15 \mathrm{~m}$ spanning piece is reached for a surface load of $13.10 \mathrm{kN} / \mathrm{m}^{2}$. On the other hand, in the solution with tensioning, the theoretical damage caused by flexocompression is produced under a load of $18.40 \mathrm{kN} / \mathrm{m}^{2}$. This represents an increase of $40.46 \%$ of its resistant capacity.

\section{Performance of the System under Asymmetrical Loads}

The objective of the connecting-rod-based self-tensioning device is to balance the loads transmitted to the supports with the tension in the tendon caused by the deformation of the connecting rods. This system is effective since the applied load is symmetrical and, therefore, equal magnitude is transmitted to both supports. Evidently, this situation is one that, as a general criterion, corresponds to the permanent action of gravity loads. However, variable actions will generate asymmetrical load situations that transmit forces of differing magnitude to the supports. In such conditions, the self-tensioning system is not capable of balancing the situation unless the device has an additional locking piece that balances the difference in the horizontal forces produced by the work of the rods, as shown in the support of the beam above in Figure 3. While this solution is very simple, its functioning is inadequate. As a matter of fact, in a piece that is in a state of equilibrium with the tendon subjected to tension due to the action of a symmetrical load system, any asymmetry in the actions on the piece would make the support device less effective in reaching the locking position to balance the increase in tension on the tendon produced in the opposite support. This would lead to an upward movement of the support to the point of reaching its locking position. Indeed, this clearly makes it so that, with loads of varying magnitude and position, which represents the actual state of the pieces, the self-tensioning devices would be in a state of permanent movement, seeking the locking positions in order to balance the ensemble, thus losing a certain degree of effectiveness.

Besides the locking device, there is a highly efficient alternative solution that completely solves the problem of asymmetrical loads. This involves anchoring the tensioning tendon in the central part of the structural floor, as shown in the span's midpoint of beam below in Figure 3. This solution brings two interesting advantages:

(i) It is very easy to implement since the anchor can be fixed by injecting epoxy adhesive or adhesive with a polyurethane base in a short length, because the force to be anchored is of a very low magnitude, as will be demonstrated further. This means that, in all analyzed cases, and according to the studies we carried out on anchors with adhesive, an adhered length of no more than $150 \mathrm{~mm}$ would be more than sufficient [25].

(ii) It allows for tensioning force of different magnitude in the two halves of the piece. In this way, the tension is greater in the area where the variable load will be applied. In an asymmetrical load situation, the reaction is greater in the support located nearer to the load action area. A greater reaction results in a higher tension force and, consequently, in a negative moment of greater magnitude. Therefore, supports with the biggest reaction experience the greatest effect of self-tensioning. This situation in which the action of the self-tensioning is more intense in the load area is further enhanced by the nonlinear effect of the rod system. In a situation with these types of 

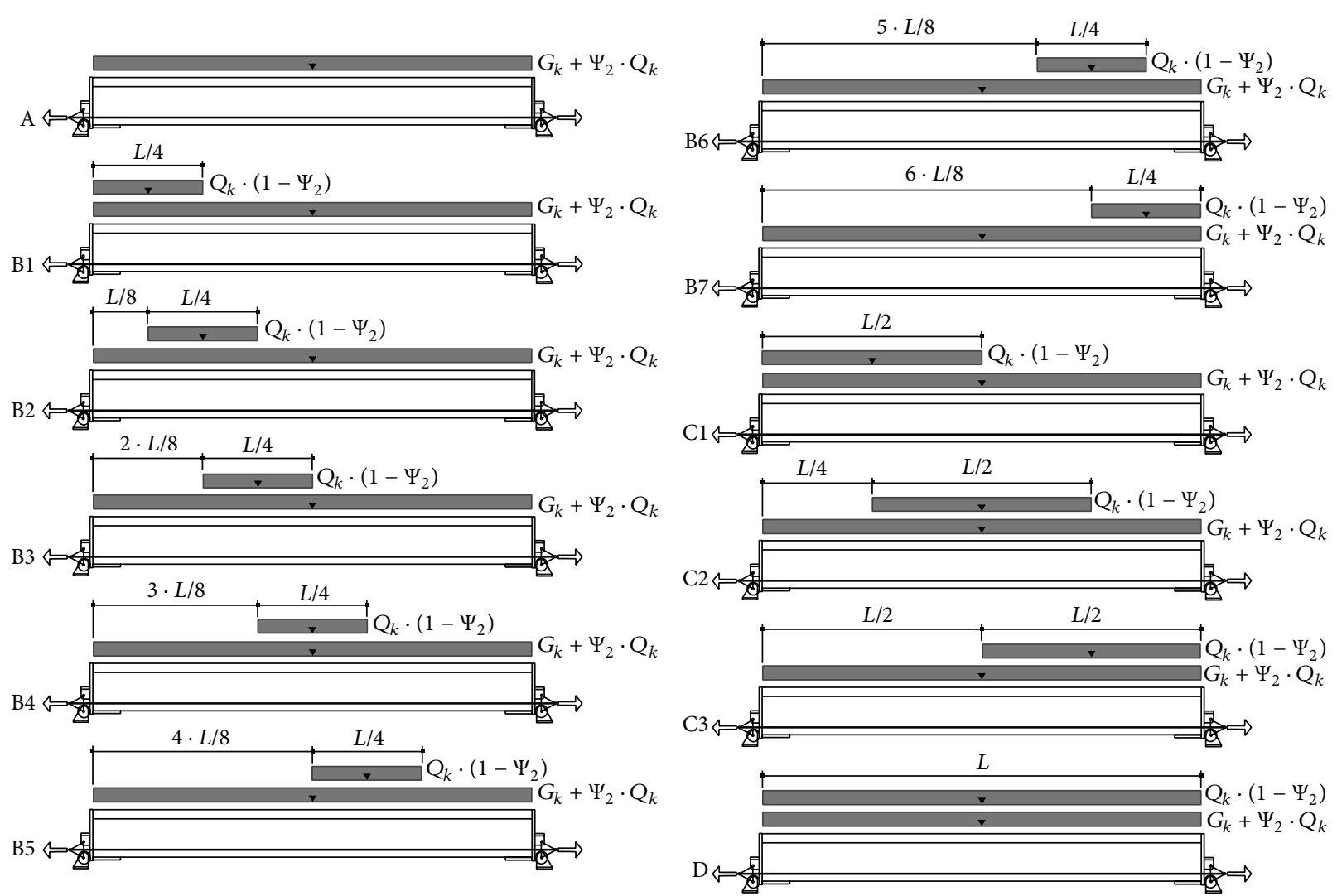

FIGURE 4: Analyzed load hypotheses.

asymmetrical loads, the sole purpose of the adhered central anchor is to balance the different tension produced in the tendon caused by the different load transmitted to the structural floor supports.

In order to check the self-tensioning system performance under asymmetrical loads, structural floors of lengths $12 \mathrm{~m}$ and $15 \mathrm{~m}$ were analyzed in two sections: (S1) section without prestressing or initial precamber and (S2) section with prestressing to a precamber of $L / 500$, with a self-tensioning system. For this analysis, it has been considered that the self-tension is achieved through the connecting rods with an initial angle of $\alpha_{0}=26.57^{\circ}$.

To determine the imposed loads, two issues must be taken into account: firstly, this type of large-span structural floor is generally associated with public-use buildings; secondly, the main purpose of the analysis is to check the performance of the structural floor under the action of the asymmetrical loads. For now, two representative situations are considered:

(i) Administrative use and public use with furnishings: $Q_{k}=3 \mathrm{kN} / \mathrm{m}^{2}$. Quasipermanent value of variable loads. $\Psi_{2}=0.3$.

(ii) Commercial areas and public use with no constraints: $Q_{k}=5 \mathrm{kN} / \mathrm{m}^{2}$. In this case, regulations establish a coefficient for the quasipermanent section of $\Psi_{2}=$ 0.6. However, for the purpose of a comparative study and with the goal of checking the functioning of the structural floor subjected to the action of highmagnitude asymmetrical loads, we have considered that $\Psi_{2}=0$. This allows us to analyze the undesirable situation of asymmetrical load which results from considering the entire use load value as variable in its position in the piece.

In Table 1, the geometric characteristics and the load values of the structural floors studied are summarized.

For the comparative study of the system performance, the following load action hypotheses were considered (Figure 4):

(A) A quasipermanent hypothesis $\left(G_{k}+\Psi_{2} Q_{k}\right)$. For the variable load of $3 \mathrm{kN} / \mathrm{m}^{2}$, the value of $0.90 \mathrm{kN} / \mathrm{m}^{2}$ corresponding to the quasipermanent fraction was considered, while for the variable load of $5 \mathrm{kN} / \mathrm{m}^{2}$, the quasipermanent section was not considered, for the previously described reasons.

(B) B1 to B7. These correspond to the quasipermanent hypothesis (A) plus the variable load with a uniform value of $Q_{k}\left(1-\Psi_{2}\right)$ applied to a length of $L / 4$ that is displaced along the piece, with a distance of $L / 8$.

(C) $\mathrm{C} 1$ to $\mathrm{C} 3$. These correspond to the quasipermanent load (A) plus the variable load with a uniform value of $Q_{k}\left(1-\Psi_{2}\right)$ applied to a length of $L / 2$ that is displaced along the piece, with a distance of $L / 4$.

(D) Total load situation $\left(G_{k}+Q_{k}\right)$. 


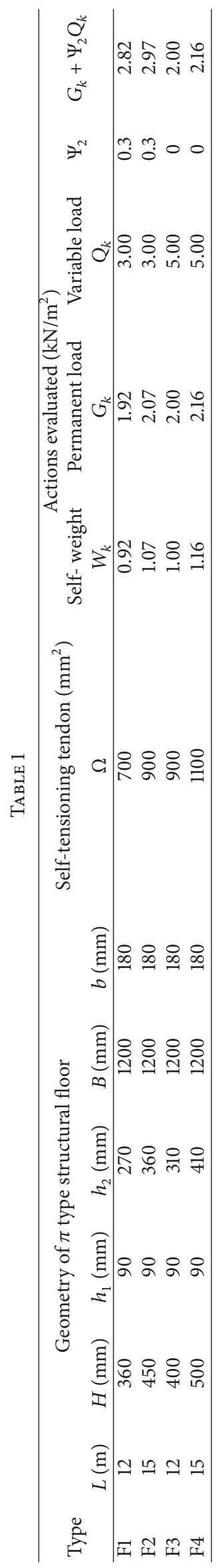




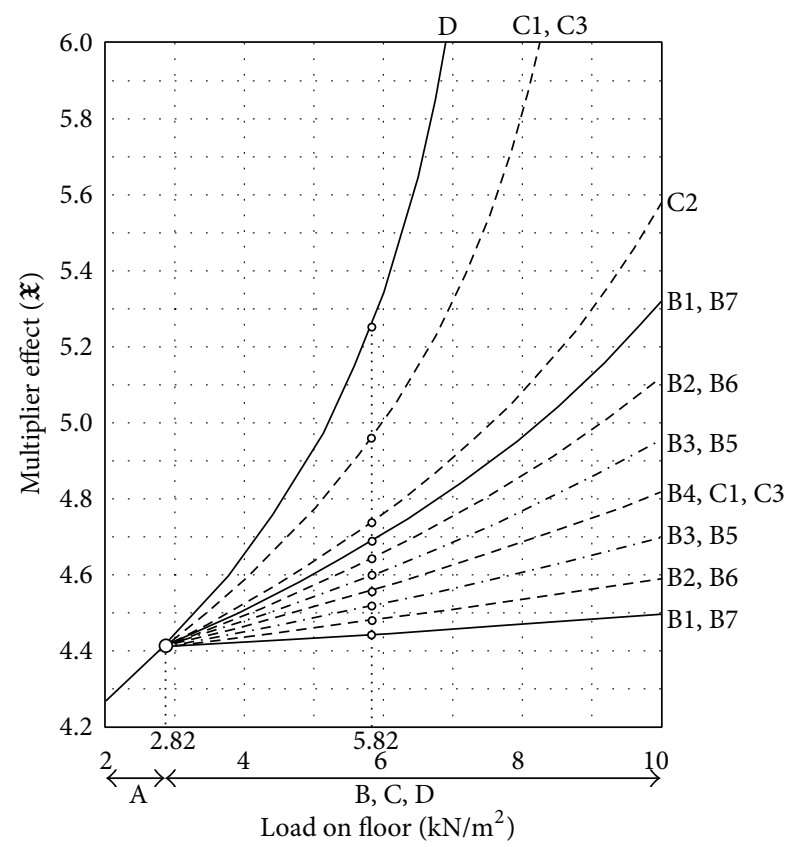

Figure 5: Multiplier ( $\mathfrak{X}) \cdot L=12 \mathrm{~m} . H=L / 33 . \alpha_{0}=26.57^{\circ}$.

Due to the differences between the reactions of the piece supports, the tension force in both ends is also different, as is the displacement of the head of the tendon. The presence of asymmetrical loads automatically raises the abovementioned singular situation: the inequality of the reactions at the supports of the structural element provokes the tensioning forces in the beam's ends to be different. Accordingly, the displacement of the tendon's head will also be different. This means that the occurrence of nonlinear geometry of the rod system is also different in both ends, so that the multiplier that generates the tension force changes with the load in different ways for both supports. This effect is reflected in Figures 5 and 6 which correspond to F1 $(L=12 \mathrm{~m}$ and $H=360 \mathrm{~mm})$ and $\mathrm{F} 4(L=15 \mathrm{~m}$ and $H=500 \mathrm{~mm})$, respectively. A multiplier device was considered, made up of two rods anchored by an eccentric tendon (Figure 1) with an initial angle of $\alpha_{0}=26.57^{\circ}$ that corresponds to a multiplier of 4.0 force value. Evidently, there is an initial stage in which the multiplier is the same for both supports. This is because these are symmetrical loads corresponding to the action of the so-called quasipermanent hypothesis (A), with a value of $2.82 \mathrm{kN} / \mathrm{m}^{2}$ for F1 and $2.16 \mathrm{kN} / \mathrm{m}^{2}$ for F4 (Table 1). After this first stage, the increases in load are always of variable load type, applied in the position that corresponds to the different hypotheses studied ( $\mathrm{B} 1$ to $\mathrm{B} 7, \mathrm{C} 1$ to $\mathrm{C} 3$, and $\mathrm{D}$ ). This means that, except for symmetrical load situations (A, $\mathrm{B} 4, \mathrm{C} 2$, and D), for each of the remaining hypotheses, two curves are obtained, corresponding to the multiplier $(\mathfrak{X})$ at each end. For example, for an F4 type piece, of $15 \mathrm{~m}$ length, in which a permanent load of $2.16 \mathrm{kN} / \mathrm{m}^{2}$ and a variable load of $5.0 \mathrm{kN} / \mathrm{m}^{2}$ are applied $\left(7.16 \mathrm{kN} / \mathrm{m}^{2}\right.$ of total load), the multipliers would be equal in both value extremes 4.30 (A), 4.52 (B4), 4.82 (C2), and 6.33 (D), due to the symmetry of the loads; in the remaining hypotheses, different multipliers are

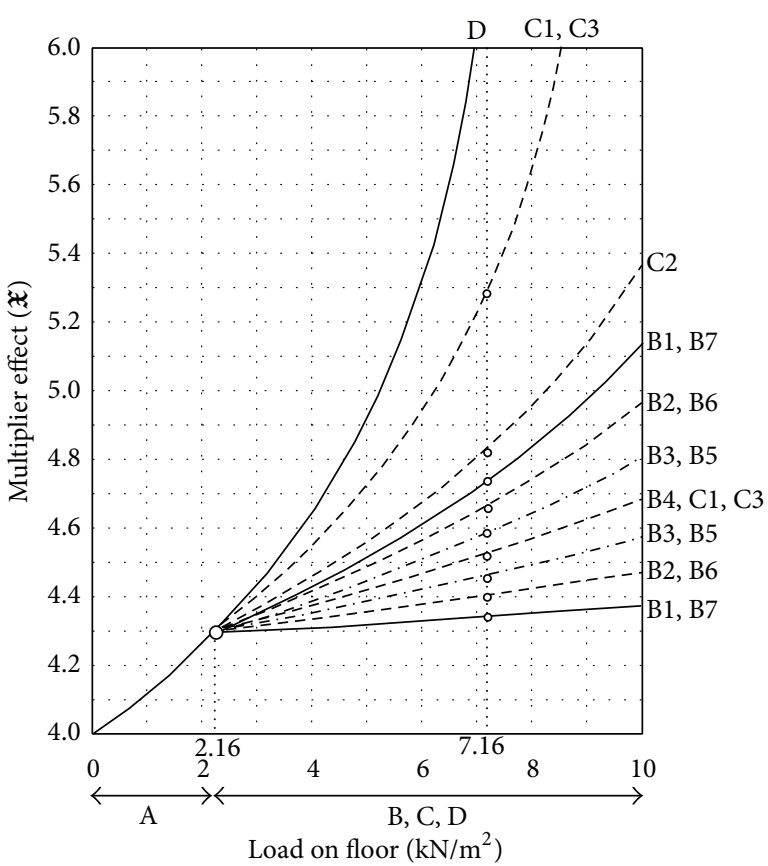

Figure 6: $\operatorname{Multiplier}(\mathfrak{X}) . L=15 \mathrm{~m} . H=L / 30 . \alpha_{0}=26.57^{\circ}$.

obtained on both ends: 4.74 and 4.35 (B1 and B7); 4.66 and 4.40 (B2 and B6); 4.59 and 4.46 (B3 and B5); 5.28 and 4.52 ( $\mathrm{Cl}$ and $\mathrm{C} 3)$.

Furthermore, the difference between the tension forces of both halves of the piece when subjected to asymmetrical loads obliges the tendon anchor in the central area to balance the different stresses on the tendon. It has been previously noted that the anchor could easily be created using an adhesive connection given that the forces transmitted had been reduced. Figures 7 and 8 show the force that would need to be anchored in F1 and F4, respectively. It is important to highlight that there is an initial section in the graphs where the force in the anchorage would be nonexistent. That is when load on floor is $\leq 2.82 \mathrm{kN} / \mathrm{m}^{2}$ and $\leq 2.16 \mathrm{kN} / \mathrm{m}^{2}$ for structural floor types F1 (Figure 7) and F4 (Figure 8), respectively. This is so for the quasipermanent load (hypothesis (A)) action due to the symmetry of its action. From this point, the force depends on the magnitude of the variable action and on the hypothesis considered. Note that even in the unfavorable situation corresponding to $\mathrm{F} 4$ and $(\mathrm{Cl})$ and (C3) hypotheses, the load that we need to anchor would be $71.02 \mathrm{kN}$, a value that is reached with an epoxy adhesive connection of approximately $150 \mathrm{~mm}$ [25].

To illustrate the performance of the self-tensioning system, the deformations of the pieces have been graphed for the different load hypotheses mentioned above. As has already been indicated, the action of the asymmetrical loads generates differing tension forces in both ends and, simultaneously, seats in the supports of differing magnitude. In Figure 9, the deformations of the F1 structural floor type corresponding to hypotheses (B1) to (B4) are shown (to make it easier to visualize, the representations of hypotheses (B5) to (B7) have been omitted, given that the results would be symmetrical). 


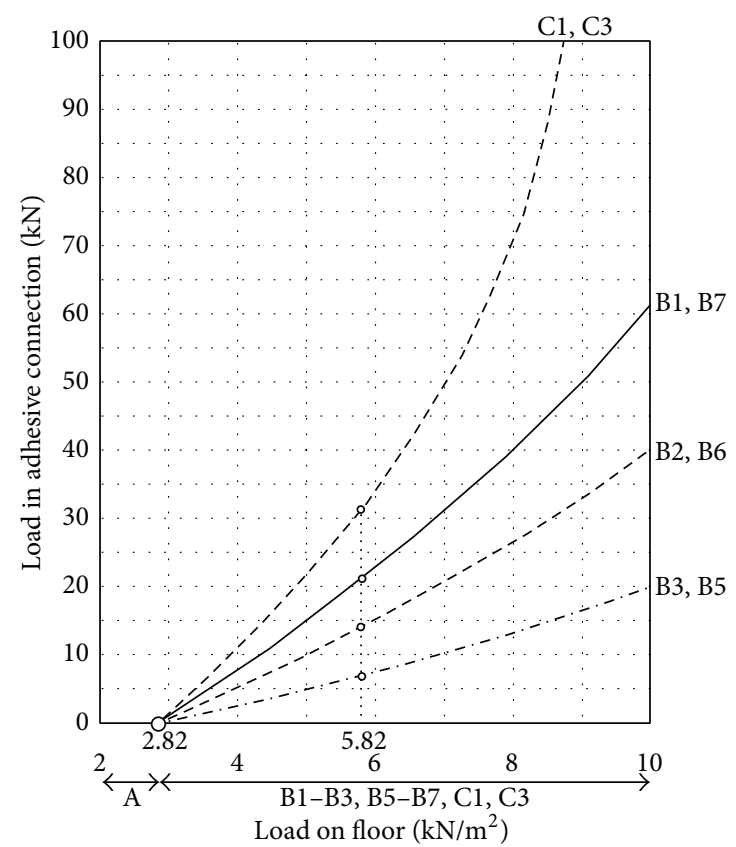

FIgURE 7: Anchor stress. $L=12 \mathrm{~m} . H=L / 33 . \alpha_{0}=26.57^{\circ}$.

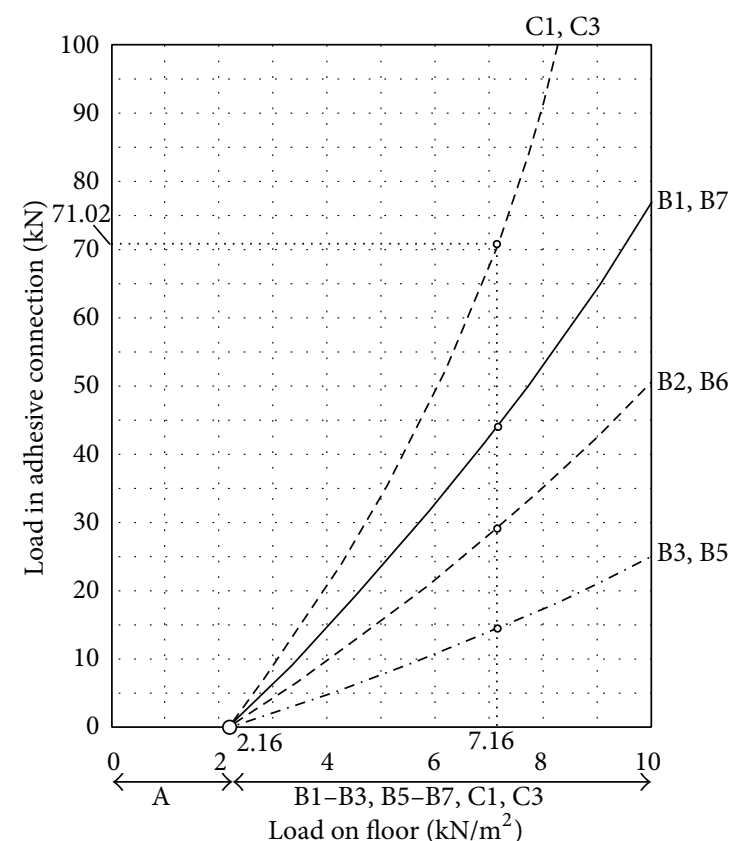

FIgURE 8: Anchor stress. $L=15 \mathrm{~m} . H=L / 30 . \alpha_{0}=26.57^{\circ}$.

The (A) and (D) hypotheses are also represented which correspond to the quasipermanent situation and total load, respectively. The (B1) hypothesis leads to a greater difference among the multiplier values at the extremes ( 4.60 and 4.43 , as shown in Figure 5), resulting in different seats at the supports. Based on the quasipermanent situation (A), in which the seat of the supports is $7.93 \mathrm{~mm}$, the variable asymmetrical action (B1) gives rise to a seat of $10.99-7.93=3.06 \mathrm{~mm}$ in one support and $8.35-7.93=0.42 \mathrm{~mm}$ in the opposite

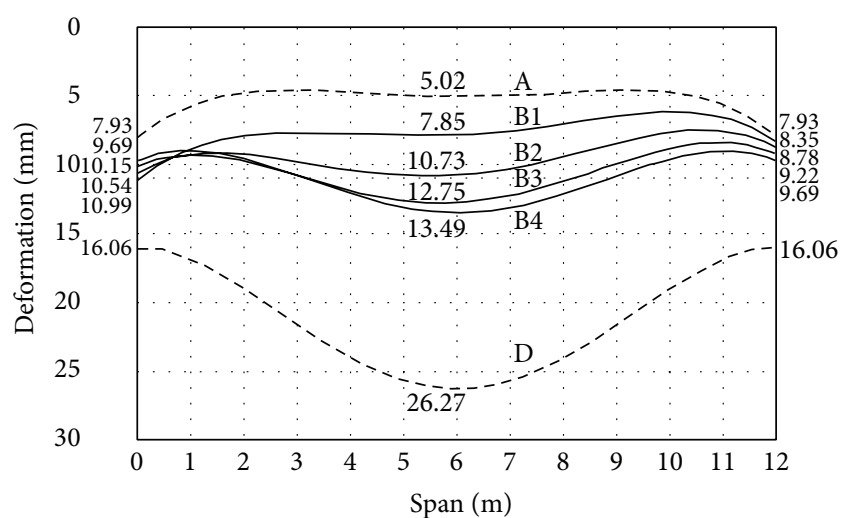

- - - Symmetrical load hypotheses (A and D)

- Asymmetrical load hypotheses (B1 to B4)

Figure 9: Deformation hypotheses (A), (B1), (B2), (B3), (B4), and (D), F1 structural floor type, section (S2).

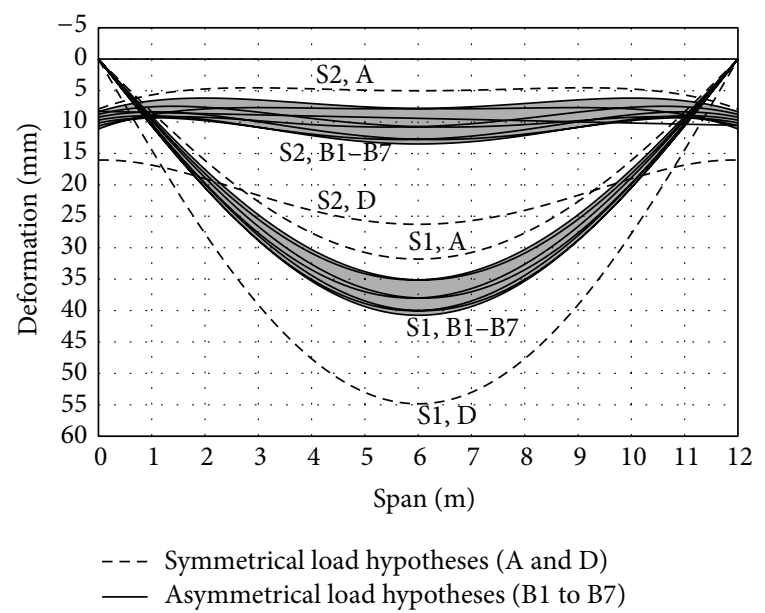

Figure 10: Deformation hypotheses (A), (B1) to (B7), and (D), F1 structural floor type, sections (S1) and (S2).

support. Considering that the maximum decrease produced in the span is $7.85 \mathrm{~mm}$, the distortion produced in the piece is only $L / 6593$. In the (B2), (B3), and (B4) hypotheses, the relative deflections are $L / 11009, L / 3889$, and $L / 3158$, respectively. Even in the hypothesis of total load (D), the displacement difference between the center and the supports is only $10.21 \mathrm{~mm}$, even though the piece is $12 \mathrm{~m}$ long, leading to a distortion of $L / 1175$. As can be clearly seen in Figure 9, in hypothesis (B1), the piece retains a precamber in relation to the straight line that connects the supports. In the case of (B2), the distortion is practically nonexistent and then progressively increases as the load shifts towards the midspan.

In Figure 10, the performance of the piece without prestressing $(\mathrm{S} 1)$ is compared with the piece with prestressing and self-tensioning system (S2). The deformations from hypotheses (A), (B1) to (B7), and (D) are graphed. The "zones" are shaded where the deformations corresponding to the hypotheses are located, with the variable load moving along 


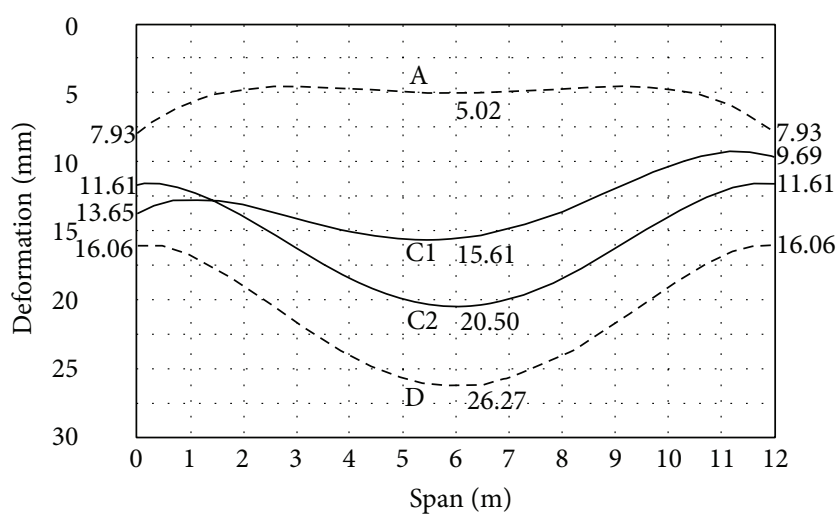

- - Symmetrical load hypotheses (A and D)

— Asymmetrical load hypotheses (C1 to C2)

Figure 11: Deformation hypotheses (A), (C1), (C2), and (D), F1 structural floor, section (S2).

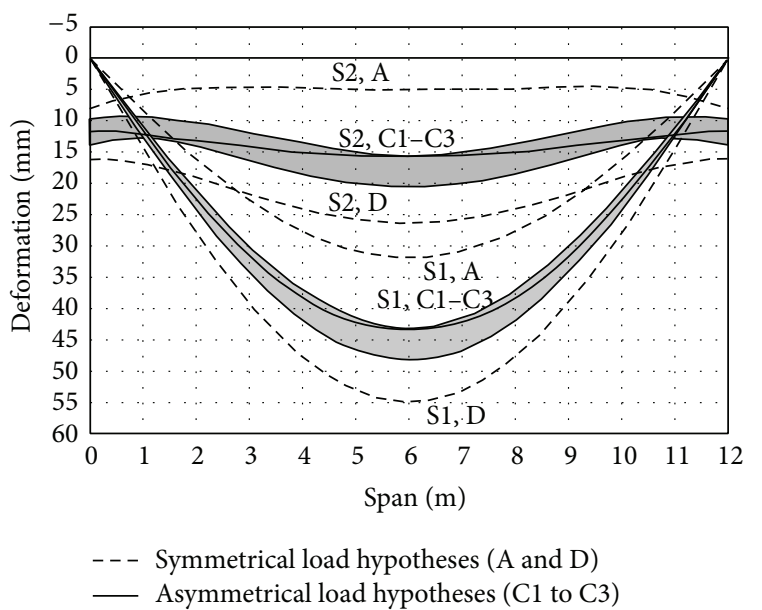

Figure 12: Deformation hypotheses (A), (C1) to (C3), and (D), F1 structural floor, sections (S1) and (S2).

the piece; this way, we can visualize the extraordinary difference between the performances that both section types, (S1) and (S2), present.

In Figure 11, the deformations corresponding to the same analyzed piece (F1 type structural floor) are displayed for hypotheses (A), (C1), (C2), and (D). Hypothesis (C1), with one-half of the beam fully loaded, leads to a greater difference between the support multipliers (4.76 and 4.51, as seen in Figure 5). The variable action leads to an increase of the seat of $5.72 \mathrm{~mm}$ in one support and $1.76 \mathrm{~mm}$ at the opposite end, with a distortion of the entire piece of $L / 2985$. For hypothesis (C2), the relative deflection reaches a value of $L / 1350$.

Figure 12 shows the clear differences in performance between the pieces without prestressing ( $\mathrm{S} 1$ ) and the pieces with prestressing and self-tensioning system (S2). Again, the shaded areas allow seeing the great effectiveness of the selftensioning system in terms of relative deflection.

The results obtained in the F3 structural floor type are similar to those corresponding to F1, since the variable load

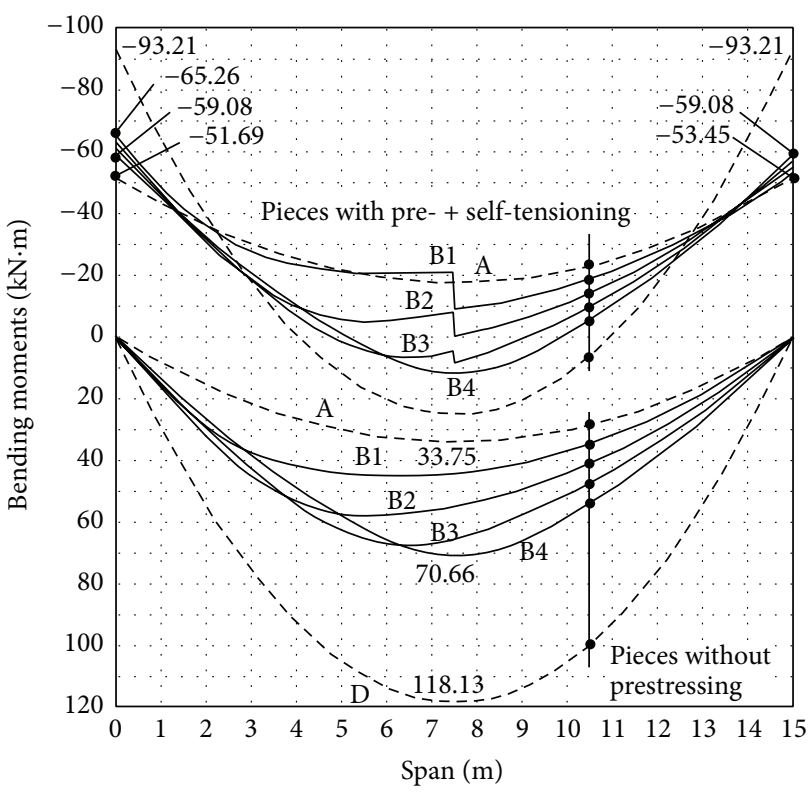

FIGURE 13: Bending moments hypotheses (A), (B1) to (B4), and (D) F4 structural floor type, sections (S1) and (S2).

increase (from $3 \mathrm{kN} / \mathrm{m}^{2}$ to $5 \mathrm{kN} / \mathrm{m}^{2}$ ) is compensated by the increase in rigidity from increasing the height (from $360 \mathrm{~mm}$ to $400 \mathrm{~mm}$ ). In the case of hypotheses (B1), (B2), (B3), and (B4), the F3 structural floor presents distortions of the following values, respectively, $L / 1111, L / 1757, L / 3659$, and $L / 5854$. For the same hypotheses, if they were applied to the F1 structural floor, it would result in the following distortion values: $L / 6593, L / 11009, L / 3889$, and $L / 3158$. In the case of the F3 structural floor, the distortion is lower in the (B3) and (B4) hypotheses than in those of (B1) and (B2), contrary to what happens with the F1 structural floor. This is a direct consequence of the fact that the variable load of $5 \mathrm{kN} / \mathrm{m}^{2}$ in (B1) and (B2) hypotheses is located very close to the supports, generating little positive bending. Nevertheless, this also generates an important autotensioning moment, so the pieces of these hypotheses get a precamber. In the F1 type, this effect has a lower incidence, as the variable load has lower magnitude. On the other hand, in the case of the F3 structural floor, the $(\mathrm{C} 1)$ and $(\mathrm{C} 2)$ hypotheses give rise to distortion values of $L / 5811$ and $L / 1799$, against the values of $L / 2985$ and $L / 1350$ corresponding to F1.

We can also analyze the significant difference in the level of structural performance, under the point of view of stresses, between the tensioned solution (S2) and the nontensioned solution (S1). In Figures 13 and 14, bending moments have been graphed for the pieces of $15 \mathrm{~m}$ span length and the different load hypotheses. Comparing the results corresponding to the pieces without prestressing with those obtained from tensioned sections, it can be seen that the tensioning produces an efficient redistribution of the stresses. The solution involving the adherence of the tendon to the central part of the piece does not only solve the force balancing resulting from the action of the rod system. Besides this, it adequately redistributes the bending stresses in 


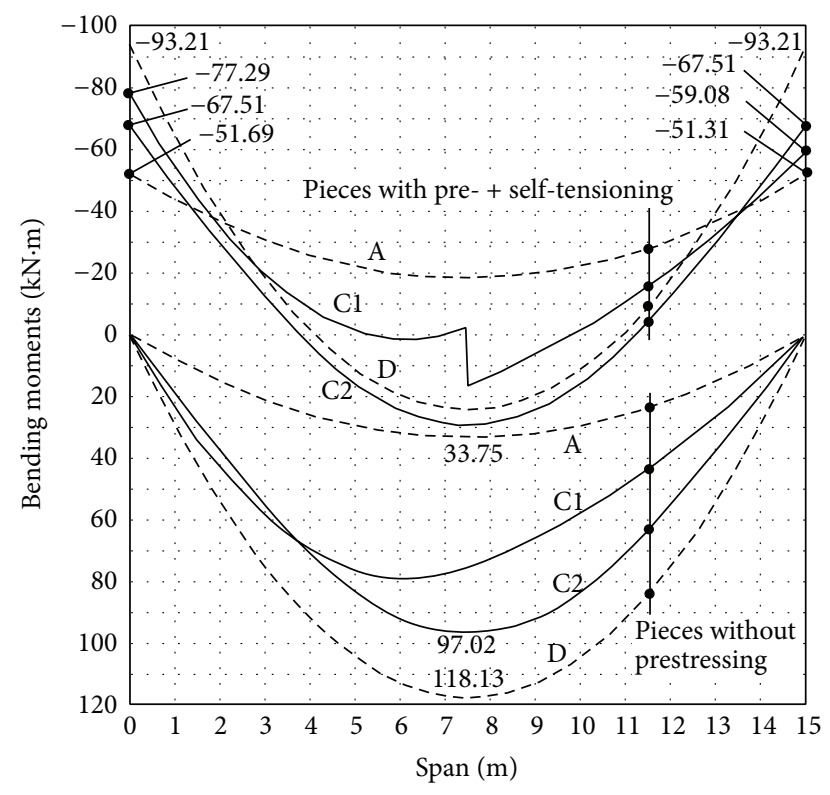

FIGURE 14: Bending moments hypotheses (A), (C1), (C2), and (D), F4 structural floor type, sections (S1) and (S2).

accordance with the acting forces. This occurs because the asymmetrical tensioning generates a greater negative moment in the part of the beam where the load is acting. The moment graphs corresponding to asymmetrical load hypothesis are represented supposing a point load in the central anchorage area. Accordingly, the load distribution in the anchoring will occur with a nonuniform distribution of the tensions throughout all the glued area. This will modify the moments graph in the anchoring area. We have selected this representation type because it does not affect the comparative analysis of sections (S1) and (S2). Besides this, the precise knowledge of the tension redistribution at the anchoring requires an experimental check that has not been carried out yet.

Results show that it is possible to easily modify the bending moments and consequently the piece deformation diagrams by varying the tension force and the geometry of the multiplier. Thus, the solution can be optimized.

\section{Conclusions}

The use of prestressing and a self-tensioning system with a multiplier mechanism, automatically activated when load is applied to the structural element, comprises a very effective solution for $\pi$-shape cross section timber structural floors.

A study was carried out comparing pieces for $\pi$-type sections with no prestress and sections with an initial prestress and a self-tensioning system, spanning $12 \mathrm{~m}$ and $15 \mathrm{~m}$, height values of $L / 33$ and $L / 30$, and for variable use loads of $3 \mathrm{kN} / \mathrm{m}^{2}$ and $5 \mathrm{kN} / \mathrm{m}^{2}$, respectively. The results show effective redistribution of bending stress and a reduction in deformations, which means the possibility of constructing slenderer timber structural floors with relative deformations below $L / 1000$ when in service.
The problems posed by the action of asymmetrical loads are effectively solved by adhering the anchor in the central part of the piece. Using this solution, tensioning strength is achieved where the magnitude is greater in precisely the area of the active load, which increases the efficiency of the system. Through the studied cases, it has been proved that the tendon can be anchored with an adhesive connection area no larger than $150 \mathrm{~mm}$ in length.

\section{Competing Interests}

The authors declare that they have no competing interests.

\section{Acknowledgments}

This research is part of the research project "High-Performance Prefabricated Systems Made of Pre-Stressed Laminated Wood without Adhered Tendons" financed by the Spanish Ministry of Economy and Finance and the European Regional Development Fund (ERDF).

\section{References}

[1] A. Borri and M. Corradi, "Strengthening of timber beams with high strength steel cords," Composites Part B: Engineering, vol. 42, no. 6, pp. 1480-1491, 2011.

[2] C. A. Issa and Z. Kmeid, "Advanced wood engineering: glulam beams," Construction and Building Materials, vol. 19, no. 2, pp. 99-106, 2005.

[3] V. De Luca and C. Marano, "Prestressed glulam timbers reinforced with steel bars," Construction and Building Materials, vol. 30, pp. 206-217, 2012.

[4] J. H. Negrão, "Prestressing systems for timber beams," in Proceedings of the World Conference on Timber Engineering (WCTE '12), vol. 1, pp. 252-261, Auckland, New Zealand, July 2012.

[5] J. Soriano, B. P. Pellis, and N. T. Mascia, "Mechanical performance of glued-laminated timber beams symmetrically reinforced with steel bars," Composite Structures, vol. 150, pp. 200207, 2016

[6] I. Glišović, B. Stevanović, and M. Todorović, "Flexural reinforcement of glulam beams with CFRP plates," Materials and Structures, vol. 49, no. 7, pp. 2841-2855, 2016.

[7] Z. W. Guan, P. D. Rodd, and D. J. Pope, "Study of glulam beams pre-stressed with pultruded GRP," Computers and Structures, vol. 83, no. 28-30, pp. 2476-2487, 2005.

[8] A. Yusof and A. L. Saleh, "Flexural strengthening of timber beams using glass fibre reinforced polymer," Electronic Journal of Structural Engineering, vol. 10, pp. 45-56, 2010.

[9] P. De La Rosa García, A. C. Escamilla, and M. N. González García, "Bending reinforcement of timber beams with composite carbon fiber and basalt fiber materials," Composites Part B: Engineering, vol. 55, pp. 528-536, 2013.

[10] A. D’Ambrisi, F. Focacci, and R. Luciano, "Experimental investigation on flexural behavior of timber beams repaired with CFRP plates," Composite Structures, vol. 108, no. 1, pp. 720-728, 2014.

[11] A. Brunner and M. Schnüriger, "Strengthening timber beams with prestressed artificial fibres: the delamination problem," in Proceedings of the COST C12 Final Conference, vol. 1, pp. 219224, 2005. 
[12] R. Kliger, M. Al-Emrani, M. Johansson, and R. Crocetti, "Strengthening timber with CFRP or steel plates-short and long-term performance," in Proceedings of the 10th World Conference on Timber Engineering (WCTE '08), vol. 1, pp. 414421, Miyazaki, Japan, June 2008.

[13] A. Buchanan, A. Palermo, D. Carradine, and S. Pampanin, "Post-tensioned timber frame buildings," Structural Engineer, vol. 89, no. 17, pp. 24-30, 2011.

[14] W. Van Beerschoten, A. Palermo, D. Carradine, and S. Pampanin, "Design procedure for long-span post-tensioned timber frames under gravity loading," in Proceedings of the 12th World Conference on Timber Engineering (WCTE '12), vol. 1, pp. 354361, July 2012.

[15] E. McConnell, D. McPolin, and S. Taylor, "Post-tensioning of glulam timber with steel tendons," Construction and Building Materials, vol. 73, pp. 426-433, 2014.

[16] T. Smith, F. C. Ponzo, A. Di Cesare et al., "Post-tensioned glulam beam-column joints with advanced damping systems: testing and numerical analysis," Journal of Earthquake Engineering, vol. 18, no. 1, pp. 147-167, 2014.

[17] F. Wanninger and A. Frangi, "Experimental and analytical analysis of a post-tensioned timber connection under gravity loads," Engineering Structures, vol. 70, pp. 117-129, 2014.

[18] B. Anshari, Z. W. Guan, A. Kitamori, K. Jung, and K. Komatsu, "Structural behaviour of glued laminated timber beams prestressed by compressed wood," Construction and Building Materials, vol. 29, pp. 24-32, 2012.

[19] J. Estévez-Cimadevila, D. Otero-Chans, E. Martín-Gutiérrez, and F. Suárez-Riestra, "Self-tensioning system for long-span wooden structural floors," Construction and Building Materials, vol. 102, pp. 852-860, 2016.

[20] European Committee for Standardization (CEN), “Timber structures-glued laminated timber and glued solid timberrequirements," EN 14080:2013, 2013.

[21] European Technical Assesment ETA-14/0349: 2014, 2014.

[22] European Committee for Standardization (CEN), "Prestressing steels-part 4: bars," prEN 10138-4:2000, 2000.

[23] European Committee for Standardization (CEN), "Eurocode 1: actions on structures-Part 1-1: general actions-densities, selfweight, imposed loads for buildings," EN 1991-1-1:2003/AC:2010.

[24] EN 1995-1-1:2004/AC:2006, European Committee for Standardization (CEN). Eurocode 5: design of timber structures. Part 1-1: General rules and rules for buildings.

[25] D. Otero-Chans, J. Estévez-Cimadevila, and E. Martín-Gutiérrez, "Withdrawal strength of threaded steel rods glued with epoxy in wood," International Journal of Adhesion \& Adhesives, vol. 44, pp. 115-121, 2013. 

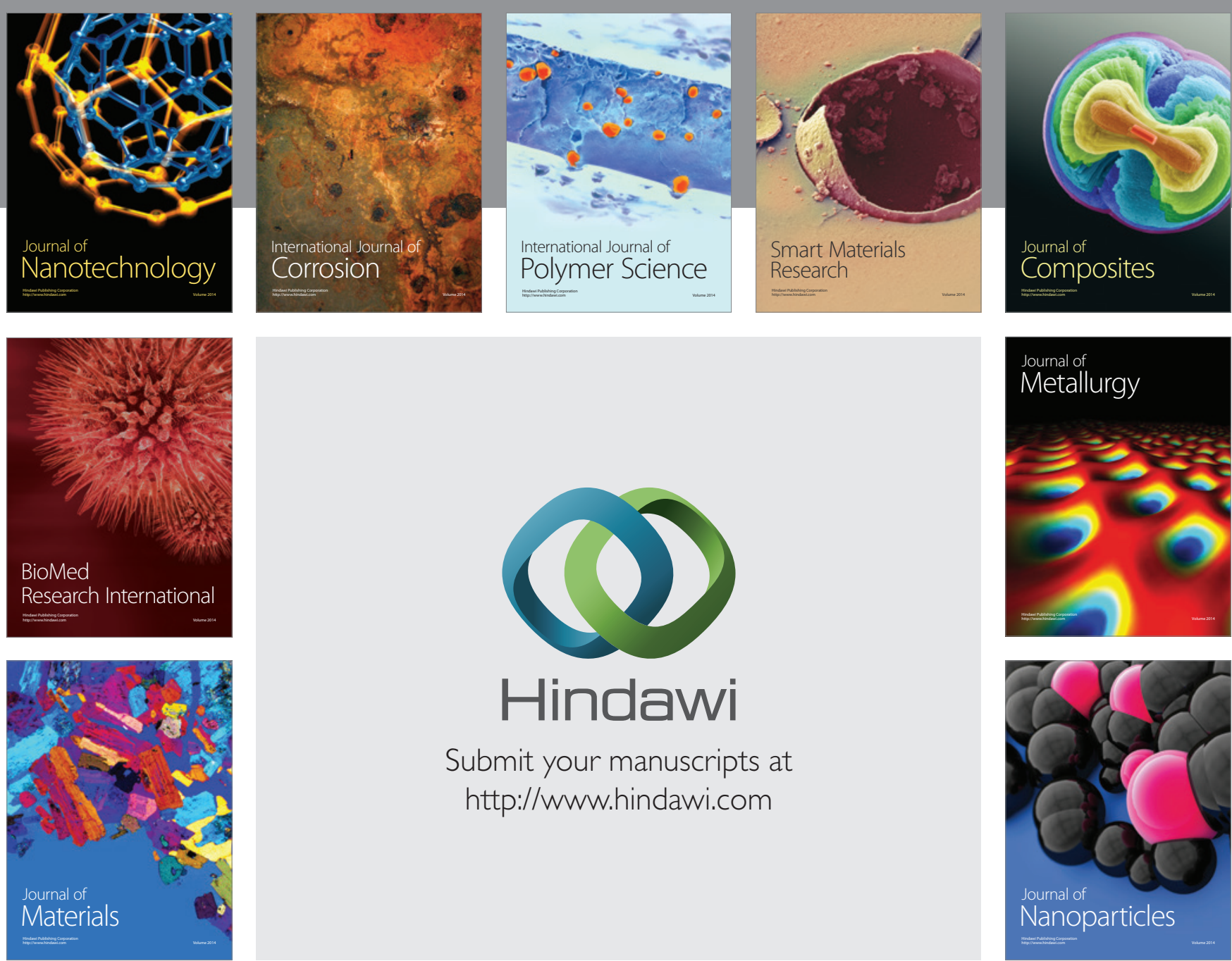

\section{Hindawi}

Submit your manuscripts at

http://www.hindawi.com

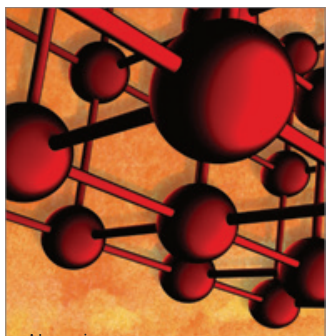

Materials Science and Engineering
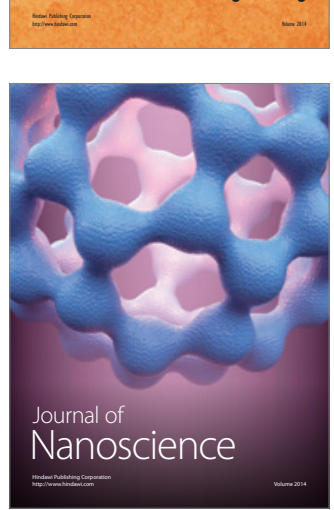
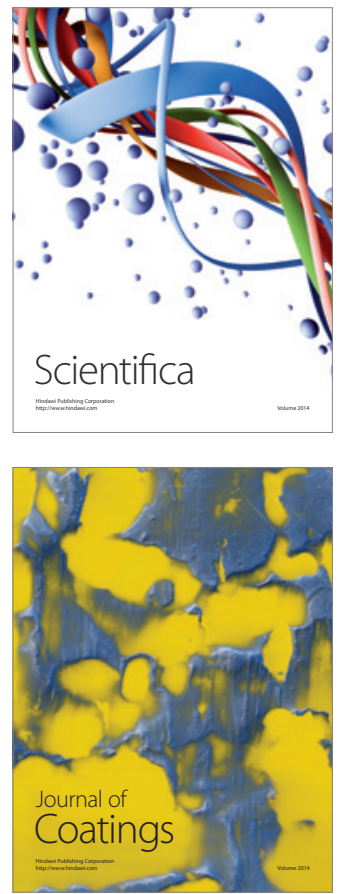
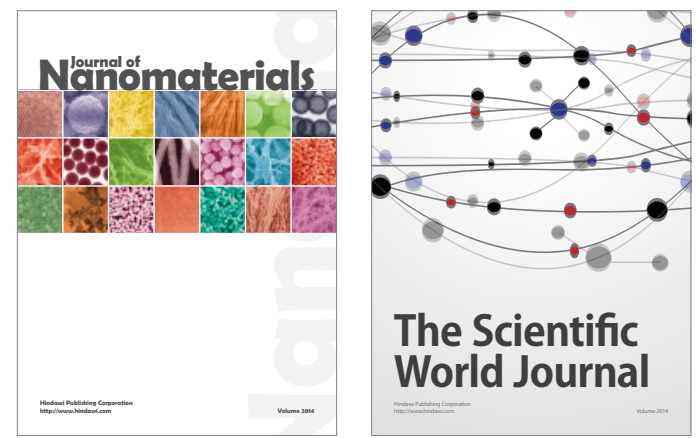

The Scientific World Journal
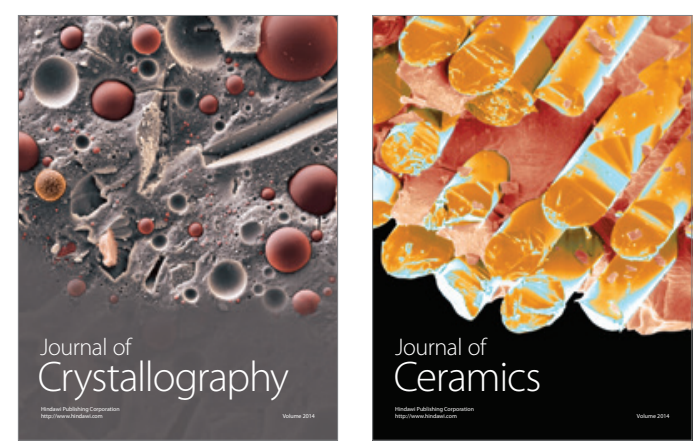
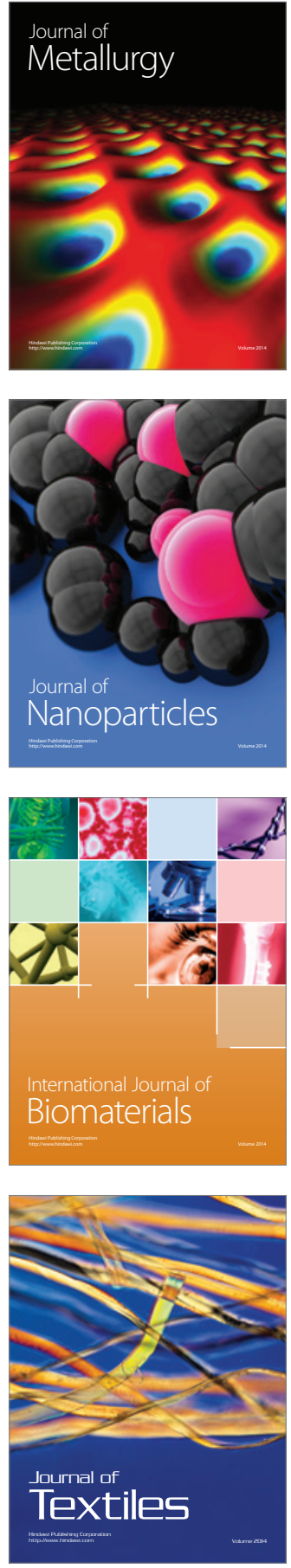